\title{
Internal particle size distribution of biofuel pellets
}

\author{
Peter Daugbjerg Jensen ${ }^{\mathrm{a}, *}$, Michäel Temmerman ${ }^{c}$, Susanne Westborg ${ }^{\mathrm{b}}$ \\ ${ }^{a}$ Danish Centre for Forest, Landscape and Planning, University of Copenhagen, Hoersholm Kongevej 11, DK-2970 Hoersholm, Denmark \\ ${ }^{\mathrm{b}}$ FORCE Technology, Park Allé 345, DK-2605 Brøndby, Denmark \\ ${ }^{\mathrm{C}}$ Centre wallon de Recherches agronomiques, Département de Génie rural, CRA-W, Chaussée de Namur, 146, B 5030 Gembloux, Belgium
}

\section{A R T I C L E I N F O}

\section{Article history:}

Received 18 September 2009

Received in revised form 18 November 2010

Accepted 23 November 2010

Available online 7 December 2010

\section{Keywords:}

Wood pellets

Straw pellets

Particle size distribution

Solid biofuel

Quality characterisation

\begin{abstract}
A B S T R A C T
Several methods for disintegration of biofuel pellets were tested and compared for their ability to break up the pellets into the original particles of the raw material. Analyses performed on softwood pellets and straw pellets concluded that wet disintegration in water at ambient temperature is insufficient for a determination of the internal particle size distribution of wood- and straw pellets. When the wet disintegration was performed with water heated to the boiling point and coupled with mechanical disintegration in terms of stirring a more complete disintegration of the pellets was obtained. Based on the results obtained in the initial study a round robin was set up including six European laboratories where the selected method was tested. In the round robin test the method combining heated water and stirring of the slurry was tested on solid biofuel pellets produced of comminute straw, deciduous wood and coniferous wood respectively. With the method a satisfactory disintegration was obtained of all three types of pellets.

Further wet disintegration of coniferous pellets was compared to a dry disintegration using a hammer mill. The dry disintegration of the coniferous pellets resulted in smaller particle sizes compared to the wet disintegration using heated water and stirring of the slurry indicating a further disintegration of the original particles in the hammer mill process.

Overall the wet disintegration combined with mechanical impact was found to be the most suitable method for disintegration of solid biofuel pellets. Combined with sieving analysis the method gives realistic image of the internal particle size distribution of solid biofuel pellets.
\end{abstract}

(c) 2010 Elsevier Ltd. All rights reserved.

\section{Introduction}

The growing focus on reduction of greenhouse gases emissions, especially carbon dioxide has led an increasing part of electricity producers to convert coal pulverized systems into co-combustion using solid biofuel in the form of comminuted wood- or straw pellets [1]. Co-combustion of biomass and coal are identified as a short term, low risk and sustainable way for reducing emissions of $\mathrm{CO}_{2}, \mathrm{SO}_{x}$ and $\mathrm{NO}_{x}$ [3]. Advantages of co-combustion are several; environmental in terms of substitution of fossil fuels with solid biofuel, technical as boiler efficiency is improved and economical as the fuel costs are reduced [1]. By that, substitution of a part of the pulverized coal by comminute pellets is an excellent possibility for long term sustainable $\mathrm{CO}_{2}$ reduction [8].

The growing consumption of pellets, both for direct combustion and for suspension combustion have increased the import of pellets from outside Europe. Considering Europe with the formal 15

\footnotetext{
* Corresponding author. Present address: Danish Technological Institute,
} Kongsvang Allé 29, DK-8000 Aarhus C, Denmark. Fax: +45 72201019.

E-mail address: peter.daugbjerg.jensen@teknologisk.dk (P.D. Jensen). countries, the use of imported biomass for electricity production could reduce by about $20 \%$ the costs related to the achievement of renewable energy use goals [5-7]. In consequence, the transport of solid biofuel pellets appears profitable both on an economical and environmental point of view, even if milling is necessary before combustion in pulverized systems. The milling shall bring the pellets into particles having the sufficient aerodynamic properties. For pulverized systems the particle size distribution of the fuel is a characteristic of main importance as it influences the fuel feeding, the ignition, the amount of unburned particles and the furnace temperature $[4,9,10]$.

The recommended particle size distribution of the fuel for cocombustion varies, Baxter recommend that all particles shall be below $6.34 \mathrm{~mm}$ with most of the particles having a size of $3 \mathrm{~mm}$ [3]. Even that the specifications of some consumers are more strict [2] the influence of the maximum biomass particle size in co-combustion is not well defined $[11,12]$. The shape and size distribution of the particles are depending on the milling parameters (hammer or knives, rotation speed, type and diameter of the grids) and on the raw material characteristics. Moreover, the hammer mill design depends on the quality of the pellets as the internal particle size distribution and the desired particle size after milling [18]. 
A method based on a wet disintegration of the pellets is commonly used for describing the internal particle size distribution of the pellets. Assuming that the internal particle size distribution of the pellets reflects the particle size distribution of the comminute pellets the method is used to estimate the behaviour of the comminute product in a suspension boiler.

The present study investigates a number of methods to describe the internal particle size distribution of solid biofuel pellets. The methods are based on either wet-disintegrations of the pellets in water and subsequent drying and sieving of the particles or on a dry disintegration by crushing the pellets in a laboratory scale hammer mill and subsequent sieving of the particles. The obtained particle size distributions from the wet-disintegration methods are compared to the particle size distribution obtained with the dry disintegration. For the present used wet disintegration method an initial study was carried out to investigate whether comparable results were obtainable between laboratories and moreover to see whether the method could be improved. The initial study gave rise to changes in the method and a round robin test with six participating laboratories was subsequently conducted for this revised method. The aim of the round robin test was to verify the revised method and to determine the variation in terms of repeatability and reproducibility in the obtained results.

\section{Materials and methods}

\subsection{Test material}

All test material origin from commercially produced biofuel pellets acquired from the Danish energy company 'DONG energy'. The pellets had a diameter of $8 \mathrm{~mm}$ and a maximum length of approximately $40 \mathrm{~mm}$, the straw pellets being slightly shorter than the wood pellets. For the initial study of the wet disintegration method two types of solid biofuel pellet was chosen. One type was produced of coniferous wood and one type produced of comminuted straw. The dry disintegration method was tested on coniferous wood pellets from the same lot used for the wet disintegration study. For the round robin test three types of solid biofuel was chosen. Beside coniferous wood and straw pellets similar to the types used in the initial study a second type of wood pellets produced of deciduous wood was included in the round robin test. For all tests, samples of $50 \mathrm{~kg}$ was acquired and subsequently divided into test portions of $300 \mathrm{~g}$ with a riffle divider (18 splits with split size of $28.2 \mathrm{~mm}$ ).

\subsection{Initial wet disintegration study}

Three laboratories participated in the initial study of the existing method which consists of a wet disintegration of the pellets and subsequently drying and determination of the particle size distribution of the obtained particles. The disintegration was performed by placing a test portion of $300 \pm 10 \mathrm{~g}$ pellets and $1200 \pm 10 \mathrm{ml}$ demineralised water at ambient temperature in a watertight container with a volume of approximately $2000 \mathrm{ml}$ for $24 \mathrm{~h}$ for disintegration. After the disintegration the test portion was transferred to a drying container. To secure that all material was transferred the disintegration container was rinsed with demineralised water into the drying container. The material was dried at $35 \pm 5^{\circ} \mathrm{C}$ in $24 \mathrm{~h}$ and subsequently left for $24 \mathrm{~h}$ to equilibrate with the ambient temperature and humidity in the laboratory.

Beside the disintegration with demineralised water at ambient temperature additional tests was performed, using demineralised water heated to boiling point and using mechanical impact as stirring with a spoon respectively to facilitate the disintegration. All types of disintegrations were performed in duplicates.
After the equilibration the test portion was divided into two portions each of $150 \pm 10 \mathrm{~g}$ by means of a riffle divider. One portion was used for moisture determination [13] and one portion was further divided into two test portions of $75 \pm 5 \mathrm{~g}$ for particle size determination.

Moisture determination was performed by drying the moisture test portion in a drying cabinet at $105^{\circ} \mathrm{C}$ for $24 \mathrm{~h} \mathrm{[13].} \mathrm{The} \mathrm{mois-}$ ture content of the equilibrated material shall be between $5 \%$ and $15 \%$ in order to avoid that the particles become brittle or agglomerates.

Duplicate particle size analysis were performed with a Retsch AS 200 control 'g' sieving machine using eight $\emptyset 200 \mathrm{~mm}$ sieves with an aperture size of (mm) 3.15 (round holes [14]), 2.8, 2.0, $1.4,1.0,0.5,0.25$ and 0.125 (mesh wire [15]). For wood pellets the sieving analysis was performed on the full portion of $75 \pm 5 \mathrm{~g}$ whereas the straw pellets was divided into two approximately equal portions and sieved in two rounds to avoid clogging of the wire gauze. The sieving time was set to $30 \mathrm{~min}$ using amplitude of $3 \mathrm{~mm}$ which secure that the sieving is complete i.e. the mass change in the sieves between two consecutive sievings is below $0,2 \%[16]$.

\subsection{Dry disintegration study}

The dry disintegration was performed in duplicates using a laboratory hammer mill fitted with six equidistantly pivoting hammers. The rotation axis are mounted on a $10 \mathrm{~mm}$ diameter steel disc with the pivoting axe centre located $12,5 \mathrm{~mm}$ from the edge of the disc, on the diameter line. The hammers are T shaped, with a square section of $5 \mathrm{~mm}$ side; the pivoting part is $37.5 \mathrm{~mm}$ long from the centre of the axis to the perpendicular part. The milling chamber has a internal diameter of $190 \mathrm{~mm}$ and a $55 \mathrm{~mm}$ width. A $160 \mathrm{~mm}$ internal diameter and $55 \mathrm{~mm}$ width grid perforated by $3 \mathrm{~mm}$ round holes is centred in the milling chamber. The rotation speed of the engine axe is $2800 \mathrm{rpm}$, and the engine has a power of $1.1 \mathrm{~kW}$.

The particle size distribution of the dry disintegrated pellets was determined as described in Section 2.2 but using seven $\emptyset 200 \mathrm{~mm}$ sieves with an aperture size in $\mathrm{mm}$ of 3.15 (round holes [13]), 2.8, 2.0, 1.4, 1.0, 0.5 and 0.25 (mesh wire [14]). The choice of sieves reflects the recommended selection from CEN/TS 15149-2 [17].

\subsection{Wet disintegration round robin test}

Six laboratories participated in the round robin test. The method used was based on the experience from the initial study. The disintegration was performed by placing a test portion of $300 \pm 10 \mathrm{~g}$ pellets and $2000 \pm 10 \mathrm{ml}$ demineralised water heated to a temperature of $95 \pm 3{ }^{\circ} \mathrm{C}$ in a container with a volume of approximately $5000 \mathrm{ml}$ and carefully mixing the pellets and water to a slurry by stirring with a spoon. The slurry was left for $24 \mathrm{~h}$ where after it was transferred to a drying container. To secure that all material was transferred the disintegration container was rinsed with demineralised water into the drying container. The material was dried for $24 \mathrm{~h}$ at $60 \pm 5^{\circ} \mathrm{C}$ in $24 \mathrm{~h}$ and subsequently left in the laboratory for $48 \mathrm{~h}$ to equilibrate with the ambient temperature and humidity in the laboratory. All disintegrations were performed in triplicates.

After the equilibration the test portion was divided into two portions each of $150 \pm 10 \mathrm{~g}$ by means of a riffle divider. One portion was used for moisture determination as described in Section 2.2 and one portion was further divided into two test portions of $75 \pm 5 \mathrm{~g}$ for particle size determination.

Particle size analyses were performed using the sieving equipment and procedure described in Section 2.3. For the two types 
of wood pellets the sieving analysis was performed on the full portion of $75 \pm 5 \mathrm{~g}$ whereas the straw pellets was divided into two approximately equal portions and sieved in two rounds to avoid clogging of the wire gauze.

\subsection{Statistics}

For comparisons of the results from the round robin test (2.4) are the $25 \%-, 50 \%$ - and $75 \%$ quantiles calculated. The variation in the particle size distribution obtained within and between the laboratories is calculated as the standard deviation:

$S D=\sqrt{\frac{(x-\bar{x})^{2}}{(n-1)}}$

where $x$ is the value, $\bar{x}$ the mean value, $n$ is the number of values.

All data, which cannot be rejected due to procedure errors, are applied in the calculation of the standard deviations. Thereby no $a$ priori identification of outliers is employed since any variation between the distributions is assumed to be within the range that is achievable with the method.

Differences between the calculated quantiles from each laboratory are identified using a one-way ANOVA with following model:

Quantile $=\alpha_{0}+\beta_{1}$ value $+\varepsilon$

where $\alpha_{0}$ and $\beta_{1}$ are the parameters for fixed effects, $\varepsilon$ the $\sim N\left(0, \sigma_{2}\right)$ and value the mean of the three replicate measurements of the particle size for the specific quantile.

Standard deviation of repeatability $\left(S_{r}\right)$ and standards deviation of reproducibility $\left(S_{R}\right)$ of the quantiles are calculated with the Mean Square from the one-way ANOVA where:

$S_{r}=\sqrt{M S_{\text {withingroups }}}$

The repeatability is calculated under test conditions where independent analysis is obtained using the same method, equipment and operator in the same laboratory on identical samples. The repeatability limit or repeatability $(r)$ is the maximum value under which is situated, with a $95 \%$ probability, the absolute value of the difference between two results obtained in conditions of repeatability.

$S_{R}=\sqrt{M S_{\text {betweengroups }}}$
The reproducibility is calculated under test conditions where independent analyses are obtained using the similar method and equipment in different laboratories on identical samples. The reproducibility limit or reproducibility $(R)$ is the maximum value under which is situated, with a $95 \%$ probability, the absolute value of the difference between two results obtained in conditions of reproducibility.

\section{Results and discussion}

\subsection{Initial wet disintegration study}

Solid biofuel pellets produced of coniferous wood and straw were tested at three different laboratories using the existing method and modifications hereof. The obtained cumulative particle size distributions indicate that there is a considerable influence from the applied disintegration method on the distribution (Figs. 1 and 2 ). For the wood pellets it is evident that using demineralised water at room temperature result in an insufficient disintegration of the pellets. Water at room temperature is prescribed in the existing method. Applying heated water and mechanical impact through stirring of the slurry improve in various degrees the disintegration of wood pellets. However, there is some overlap in the particle size distribution curves between the three methods i.e. water at room temperature, heated water and water at room temperature combined with stirring of the slurry (large circle in Fig. 1). Combining the two effects, heated water and stirring of the slurry, resulted in a more complete disintegration which is seen as the thick solid distribution curves which are separated in the upper part of Fig. 1 (HW + STG, the small circle).

The disintegration of the straw pellets was much more complicated and some of the experiments were abandoned. In some of the experiments the material absorbed all of the $1200 \mathrm{ml}$ water and in several of the experiments was found agglomerated particles in the material for the sieve analysis. Compared to the tests using water at ambient temperature (Fig. 2, W), the tests applying heated water ( $\mathrm{HW}$ ) improved the disintegration. Opposite the tests using water at ambient temperature and stirring $(\mathrm{W}+\mathrm{Stg})$ only improved the disintegration in one of the five performed tests. Finally the one test applying both heated water and stirring $(\mathrm{HW}+\mathrm{Stg})$ showed the best disintegration compared to all other combinations. (Fig. 2). By that it was decided to proceed with a round robin test using the method where the two effects, heated water and stirring, are combined.

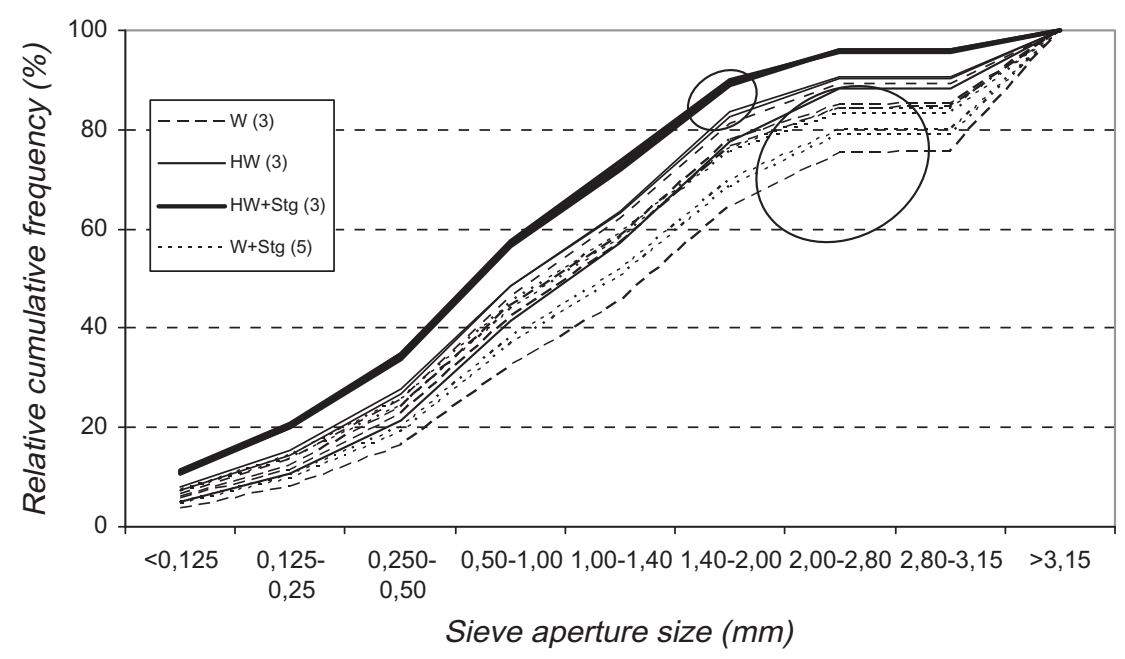

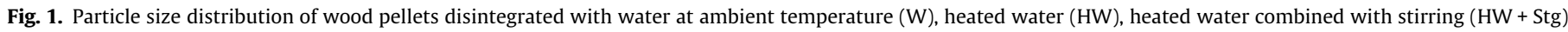

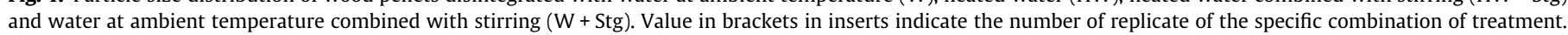




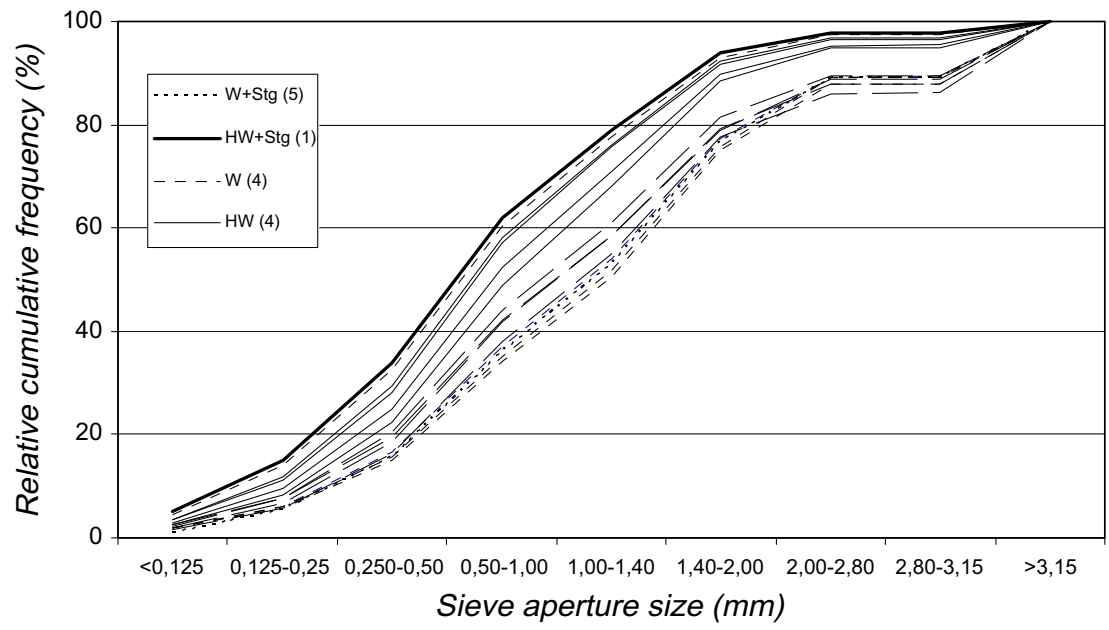

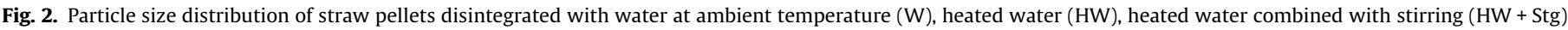

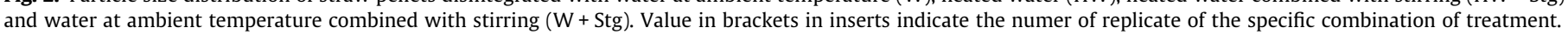

\subsection{Dry disintegration study}

Solid biofuel pellets from coniferous wood was disintegrated in a hammer mill as described in Section 2.3 at one laboratory. The test was performed on three samples in triplicates and the obtained particle size distributions show smaller particle sizes for the samples disintegrated with a hammer mill compared to the particle size distributions for wet disintegrated pellets (Fig. 3). The difference is a consequence of both the aperture size of the sieve applied to the hammer mill and the hammer mill's further disintegration of the particles into even smaller particles. Applying other aperture sizes would result in particle size distribution that would differ from the present. As a mean for estimating the particle size distribution of the pellet powder after the hammer mill at a specific production facility a method using dry disintegration in laboratory scale hammer mills could be considered. The laboratory hammer mill should then be fitted with sieves having an aperture size corresponding to the full scale hammer mill. However, the obtained results will then only be valid for the specific laboratory and full scale hammer mill and therefore not applicable as a standard test method for inter-laboratory comparisons.

\subsection{Wet disintegration round robin test}

Solid biofuel pellets produced of coniferous and deciduous wood and comminuted straw were tested in a round robin test at six different laboratories. Except for one laboratory the obtained particle size distributions of the disintegrated deciduous wood pellets showed very little variation (Fig. 4). The reason to the large deviation for the one laboratory is assumed to be use of too small amplitude in the sieving operation compared to prescribed amplitude of $3 \mathrm{~mm}$. The amplitude is identified to have a significant influence on the result of a sieving operation [16] and the deviating result was excluded in the calculation of repeatability and reproducibility. As with the coniferous wood pellets the particle size distribution of the deciduous wood pellets was very similar between five of the six laboratories (Fig. 4). The exception is the one laboratory which also obtained deviating results for the coniferous wood pellets and the deviating result was here also excluded in the calculation of the repeatability and reproducibility (Table 2).

The sieving of the straw pellet material caused problem in three of the laboratories where mass losses of the disintegrated material during the sieving operations caused rejection of the results. However, for the three laboratories where the disintegration of straw

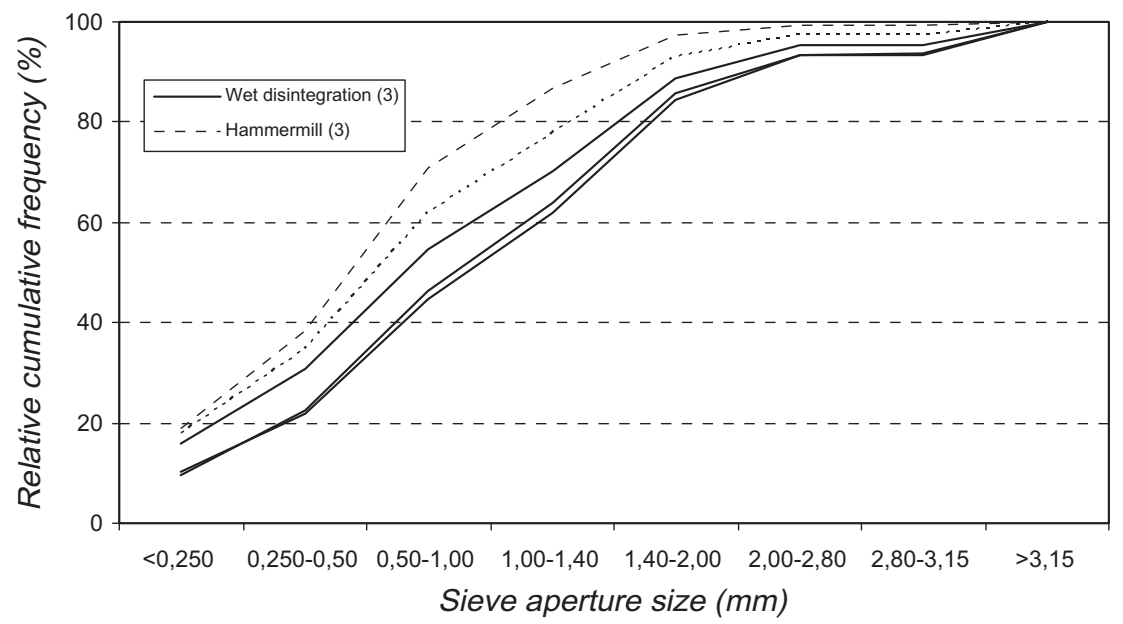

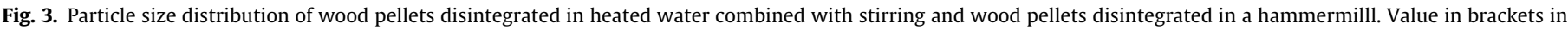
inserts indicate the number of replicate of the specific combination of treatment. 

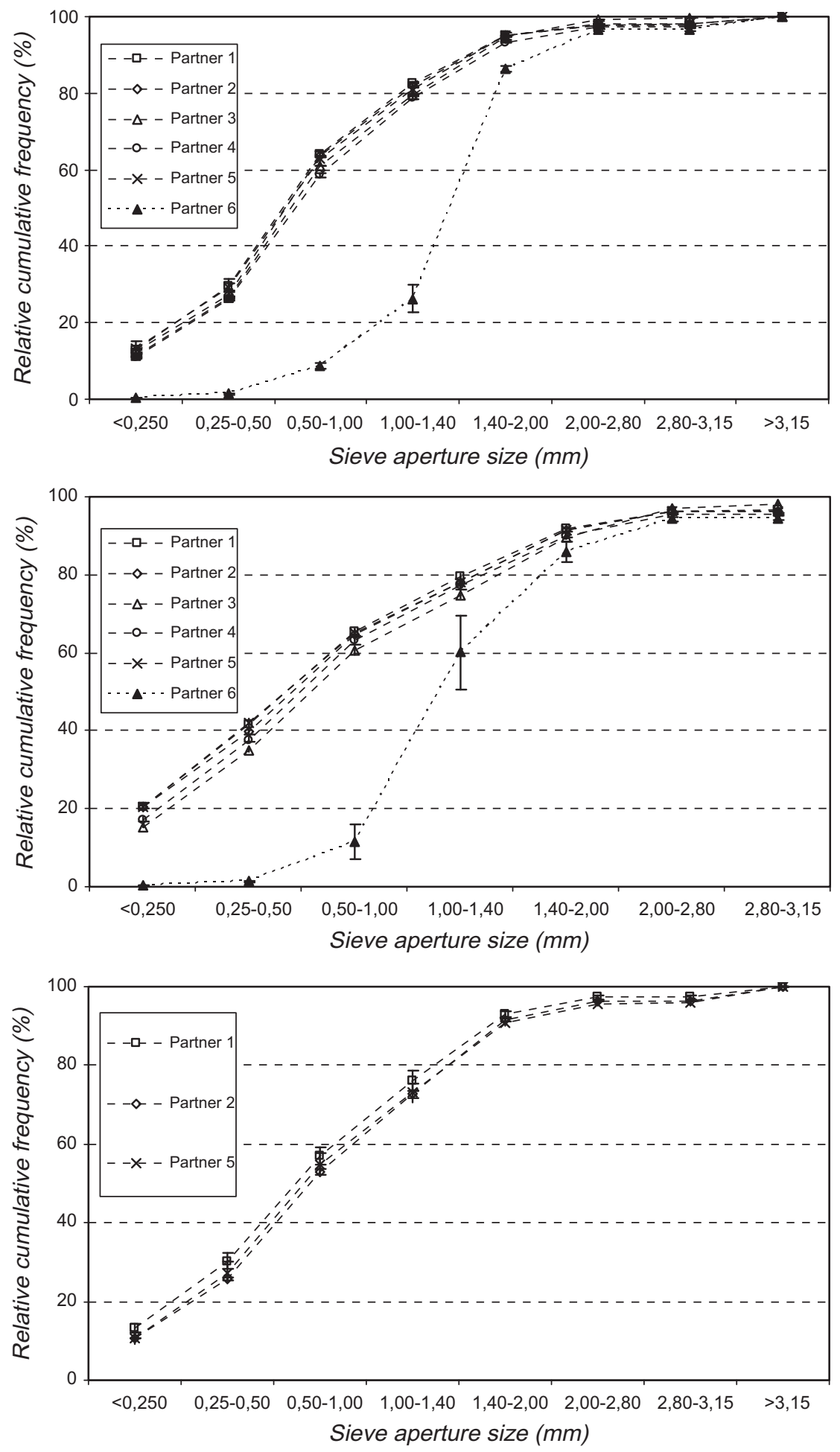

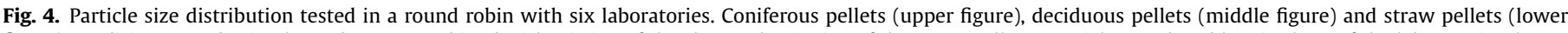

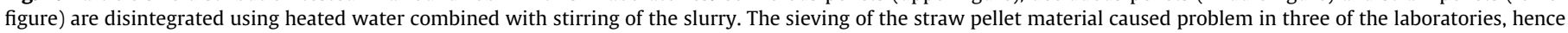
only the results from three of the six laboratories are presented.

pellets was completed without problems the resulting particle size distributions was very similar (Fig. 4). In the following evaluation of the method concerning straw pellets only the results from three of the six laboratories are used.

The mean value, the standard deviation (SD) and the coefficient of variance (CV) at the 25\%-, 50\%- and $75 \%$ quantile for the cumulative particle size distributions of straw-, coniferous- and deciduous pellets is presented in Table 1 . The coefficient of variation expresses the standard deviation as a percentage of the sample mean making the size of variation relative of the size of observation. In all but three tests (Lab 2, straw and Labs 3 and 4 deciduous) the $\mathrm{CV}$ decrease with increasing quantiles indicating that the relative accuracy of the particle size determinations decline with decreasing particle size. This most likely reflects the 
Table 1

Mean value, standard deviation and coefficient of variance for the $25 \%$-, 50\%- and $75 \%$ quantiles from the particle size distribution of the tested solid biofuel pellets.

\begin{tabular}{|c|c|c|c|c|c|c|c|c|c|c|}
\hline \multirow[t]{2}{*}{ Lab } & \multirow[t]{2}{*}{ Quantiles } & \multicolumn{3}{|c|}{ Straw pellets } & \multicolumn{3}{|c|}{ Deciduous wood pellets } & \multicolumn{3}{|c|}{ Coniferous wood pellets } \\
\hline & & $25 \%$ & $50 \%$ & $75 \%$ & $25 \%$ & $50 \%$ & $75 \%$ & $25 \%$ & $50 \%$ & $75 \%$ \\
\hline \multirow[t]{3}{*}{1} & Mean $(\mathrm{mm}<)$ & 0.42 & 0.87 & 1.38 & 0.30 & 0.68 & 1.27 & 0.43 & 0.80 & 1.24 \\
\hline & $\mathrm{SD}(\mathrm{mm}<)$ & 0.025 & 0.041 & 0.054 & 0.011 & 0.020 & 0.023 & 0.011 & 0.013 & 0.015 \\
\hline & $\mathrm{CV}$ & 5.81 & 4.71 & 3.91 & 3.75 & 2.92 & 1.81 & 2.63 & 1.57 & 1.25 \\
\hline \multirow[t]{3}{*}{2} & Mean $(\mathrm{mm}<)$ & 0.49 & 0.95 & 1.47 & 0.31 & 0.71 & 1.31 & 0.46 & 0.81 & 1.25 \\
\hline & $\mathrm{SD}(\mathrm{mm}<)$ & 0.006 & 0.011 & 0.026 & 0.007 & 0.010 & 0.017 & 0.014 & 0.005 & 0.003 \\
\hline & $\mathrm{CV}$ & 1.32 & 1.19 & 1.75 & 2.21 & 1.48 & 1.30 & 3.05 & 0.63 & 0.23 \\
\hline \multirow[t]{3}{*}{3} & Mean $(\mathrm{mm}<)$ & - & - & - & 0.37 & 0.80 & 1.41 & 0.48 & 0.84 & 1.30 \\
\hline & $\mathrm{SD}(\mathrm{mm}<)$ & - & - & - & 0.002 & 0.012 & 0.032 & 0.005 & 0.003 & 0.002 \\
\hline & $\mathrm{CV}$ & - & - & - & 0.57 & 1.46 & 2.30 & 0.98 & 0.30 & 0.13 \\
\hline \multirow[t]{3}{*}{4} & Mean $(\mathrm{mm}<)$ & - & - & - & 0.34 & 0.74 & 1.33 & 0.48 & 0.87 & 1.33 \\
\hline & $\mathrm{SD}(\mathrm{mm}<)$ & - & - & - & 0.006 & 0.014 & 0.028 & 0.006 & 0.007 & 0.008 \\
\hline & $\mathrm{CV}$ & - & - & - & 1.64 & 1.92 & 2.11 & 1.29 & 0.84 & 0.60 \\
\hline \multirow[t]{3}{*}{5} & Mean $(\mathrm{mm}<)$ & 0.47 & 0.91 & 1.46 & 0.30 & 0.68 & 1.31 & 0.43 & 0.81 & 1.27 \\
\hline & $\mathrm{SD}(\mathrm{mm}<)$ & 0.036 & 0.052 & 0.079 & 0.011 & 0.023 & 0.037 & 0.035 & 0.031 & 0.035 \\
\hline & $\mathrm{CV}$ & 7.71 & 5.71 & 5.38 & 3.61 & 3.35 & 2.83 & 8.13 & 3.84 & 2.78 \\
\hline \multirow[t]{3}{*}{6} & Mean $(\mathrm{mm}<)$ & - & - & - & 1.11 & 1.32 & 1.72 & 1.38 & 1.63 & 1.88 \\
\hline & $\mathrm{SD}(\mathrm{mm}<)$ & - & - & - & 0.045 & 0.065 & 0.157 & 0.075 & 0.026 & 0.014 \\
\hline & $\mathrm{CV}$ & - & - & - & 4.07 & 4.94 & 9.12 & 5.45 & 1.57 & 0.74 \\
\hline
\end{tabular}

Table 2

Performance characteristic for the method calculated as repeatability and reproducibility.

\begin{tabular}{cllllllr}
\hline Material & $\begin{array}{l}\text { Quantiles } \\
(\%)\end{array}$ & $N$ & $\begin{array}{l}X \\
m m\end{array}$ & $\begin{array}{l}S_{r} \\
(\mathrm{~mm})\end{array}$ & $\begin{array}{l}S_{R} \\
(\mathrm{~mm})\end{array}$ & $\begin{array}{l}S_{r} \\
(\%)\end{array}$ & $S_{R}(\%)$ \\
\hline Coniferous & 25 & 5 & 0.46 & 0.018 & 0.039 & 3.94 & 8.53 \\
pellets & 50 & 5 & 0.83 & 0.016 & 0.049 & 1.94 & 5.93 \\
& 75 & 5 & 1.28 & 0.018 & 0.063 & 1.40 & 4.92 \\
Deciduous & 25 & 5 & 0.33 & 0.0082 & 0.055 & 2.51 & 16.80 \\
pellets & 50 & 5 & 0.72 & 0.016 & 0.089 & 2.22 & 12.36 \\
& 75 & 5 & 1.33 & 0.028 & 0.087 & 2.11 & 6.54 \\
Comminuted & 25 & 3 & 0.46 & 0.025 & 0.056 & 5.46 & 12.23 \\
straw & 50 & 3 & 0.91 & 0.039 & 0.067 & 4.30 & 7.37 \\
& 75 & 3 & 1.44 & 0.057 & 0.092 & 3.96 & 6.31 \\
\hline
\end{tabular}

$N$ : number of values, $X$ : mean value, $s_{r}$ : estimate of repeatability, $S_{r}$ : estimate of relative repeatability, $S_{R}$ : estimate of reproducibility, $S_{R}$ : estimate of relative reproducibility.

increasing probability of clogging of the openings in the sieves with small apertures.

The repeatability was found to be smaller than the reproducibility indicating that the disintegration and sieving procedure varies between the laboratories and thereby influence the result of the method.

\section{Conclusion}

The result of the initial wet disintegration study illustrated that wet disintegration in water at ambient temperature is an unsuitable method for determining the internal particle size distribution of wood- and straw pellets. The method does not adequately separate the particles in the pellets from each other and thereby result in an overestimation of larger particles. When the wet disintegration was performed with water heated to the boiling point and coupled with mechanical disintegration in terms of stirring a more complete disintegration of the pellets was obtained. In the round robin test the method combining the use of heated water and stirring of the slurry was tested on solid biofuel pellets produced of comminuted straw and deciduous- and coniferous wood. With this revised method a satisfactory disintegration was obtained of all three types of pellets.

The dry disintegration of coniferous pellets resulted in smaller particle sizes compared to the wet disintegration using heated water and stirring of the slurry. The particle size distribution of the dry disintegrated pellets to a large extend reflects aperture size of the applied sieves in the hammer mill and the further comminution by the hammer mill of the disintegrated particles.

It is not possible from the present study to identify whether wet or dry disintegration as applied here, describes the resulting particles size distribution of a large scale hammer milling operation in the best manner. However, as shown in the round robin test the revised wet disintegration method gives highly repeatable and reproducible results and the method may provide both a relative measure of the particle size distribution of the produced fuel powder in a large scale milling operation and the particle size distribution of the raw material used for the pellet production respectively. Further, the wet disintegration method can be conducted by any laboratory having access to sieving equipment, whereas the dry disintegration demands a hammer mill and a procedure which secure that the dry disintegration results in comparable results between laboratories. By comparing results obtained with the wet disintegration method to the particle size distribution for the actual produced fuel powder in large scale hammer mills a functional relationship might be constructed. The relationship would be explicit for the specific hammer mill and the operation hereof.

\section{Acknowledgements}

The research was supported by energinet.dk (PSO 5297). The authors would like to express their gratitude to the following laboratories which also participated in the round robin test: DONG energy, Denmark, ENAS Oy, Finland, Technologie- und Förderzentrum Nachwachsende Rohstoffe (TFZ), Germany.

\section{References}

[1] Demirbas A. Sustainable cofiring of biomass with coal. Energy Convers Manage 2003;44:1465-79.

[2] Ryckmans Y, Allard P, Liegeois B, Mewissen D. Conversion of a pulverized coal power plant to $100 \%$ wood pellets in Belgium. In: Proceedings of the second conference on pellets, Jönköping, Sweden; 30 May-1 June 2006. p. 59-61.

[3] Baxter L. Biomass-coal co-combustion: opportunity for affordable renewable energy. Fuel 2005;84:1295-302.

[4] Nishiyama A, Shimojima H, Ishikawa A, Itaya Y, Kambara S, Moritomi H, et al. Fuel and emissions properties of Stirling engine operated with wood powder. Fuel 2007;86:2333-42.

[5] Hamelinck CN, Suurs RAA, Faaij APC. International bioenergy transport costs and energy balance. Biomass Bioenergy 2005;29:114-34. 
[6] Bjerg J. The Danish pellet boom - precoditions for successful market penetration. In: Proceedings of the second world conference on biomass for energy, industry and climate protection, Rome, Italy; 10-14 May 2004. p. 1697-98.

[7] Skytte K, Meibom P, Capral Henriksen T. Electricity from biomass in the European union - with or without biomass import. Biomass Bioenergy 2006;30:385-92.

8] Wahlund B, Yan J, Westermark M. Increasing biomass utilisation in energy systems: a comparative study of $\mathrm{CO}_{2}$ reduction and cost for different bioenergy processing options. Biomass Bioenergy 2004;26:531-44.

[9] Paulrud S, Nilsson C. The effects of particle characteristics on emissions from burning wood fuel powder. Fuel 2004;83:813-21.

[10] Tmej Ch, Haselbacher H. Development of wood powder feeding into gas turbine combustion chambers. In: 1 st world conference on biomass fir energy and industry, Sevilla, Spain; 5-9 June 2000. p. 783-86.

[11] Demirbas A. Potential applications of renewable energy sources, biomass combustion problems in boiler power systems and combustion related environmental issues. Prog Energy Combust Sci 2005;31:171-92.
[12] Narayanan KV, Natarajan E. Experimental studies on cofiring of coal and biomass blends in India. Renew Energy 2007;32:2548-58.

[13] CEN/TS 14774-1:2004. Solid biofuels - methods for determination of moisture content - oven dry method - part 1 : total moisture - reference method.

[14] ISO 3310-2. Test sieves, technical requirements and testing; part 2: test sieves of perforated metal plate, 3rd ed. (1990-11-01).

[15] ISO 3310-1. Test sieves - technical requirements and testing; part 1: test sieves of metal wire cloth (2000-07-15).

[16] Jensen PD, Westborg S. Fysisk karakterisering af biobrændsler (Physical characterisation of solid biofuels). Report from WP2 of the PSO 5297; 2008 (in Danish with English abstract).

[17] CEN/TS 15149-2:2006. Solid biofuels - method for the determination of particle size distribution - part 2: vibrating screen method using sieve aperture of $3.15 \mathrm{~mm}$ and below.

[18] Chamayou A, Fages J. Broyage dans les industries agroalimentaires, In: Technologie des pulvérulents dans les IAA, Melcion, Ilari, Lavoisier, Paris; 2003. p. 375-406. 